\title{
TUMOR NECROSIS FACTOR- $\alpha$ AND INSULIN RESISTANCE IN PATIENTS WITH NONALCOHOLIC FATTY LIVER DISEASE IN COMBINATION WITH TYPE 2 DIABETES MELLITUS
}

Zhuravlyova L., Ognieva O.

Kharkiv National Medical University, Ukraine

Department of internal medicine №3 (www.vnmed3.kharkiv.ua; e-mail: vnmed@gmail.com)

Results. The mean level of TNF- $\alpha$ was significantly

Tumor necrosis factor- $\alpha(\mathrm{TNF}-\alpha)$ is an adipokine that can cause the cytotoxic effects and stimulate the apoptosis, impairing liver function. There is a need in further study of TNF- $\alpha$ influence on liver cells properties and its role in the pathogenesis of nonalcoholic fatty liver disease (NAFLD) against a background of type 2 diabetes mellitus (T2DM) in patients with different trophological status.

Purpose. The study was designed to assess the relationship between the level of TNF- $\alpha$ and indices of carbohydrate metabolism in patients with NAFLD and its combination with T2DM with different trophological status.

Subjects. The study was performed on 90 patients with isolated NAFLD and in combination with T2DM with normal weight and obesity (body mass index $\geq 30 \mathrm{~kg} / \mathrm{m}^{2}$ ). All patients were divided into 3 groups: group $1(\mathrm{n}=20)$ comprized the patients with isolated NAFLD, group 2 $(n=20)$ patients with combination of NAFLD and T2DM with normal body weight and group $3(n=50)$ patients with comorbid disorder and obesity. The controls $(n=20)$ were apparently healthy individuals.

Methods. The study was carried out using the following methods: the level of serum fasting blood glucose (FBG) was determined by glucose oxidase method ("Diabetes-Test" kit), immunoreactive insulin (IRI) - by immunosorbent sandwich method («DRG» kit). HOMA-IR was calculated using the formula: HOMA = IRI FBG/22.5. The level of TNF$\alpha$ was determined by immunoassay method ("Vector-Best" kit).

Pис. 1 GROUPS OF PATIENTS

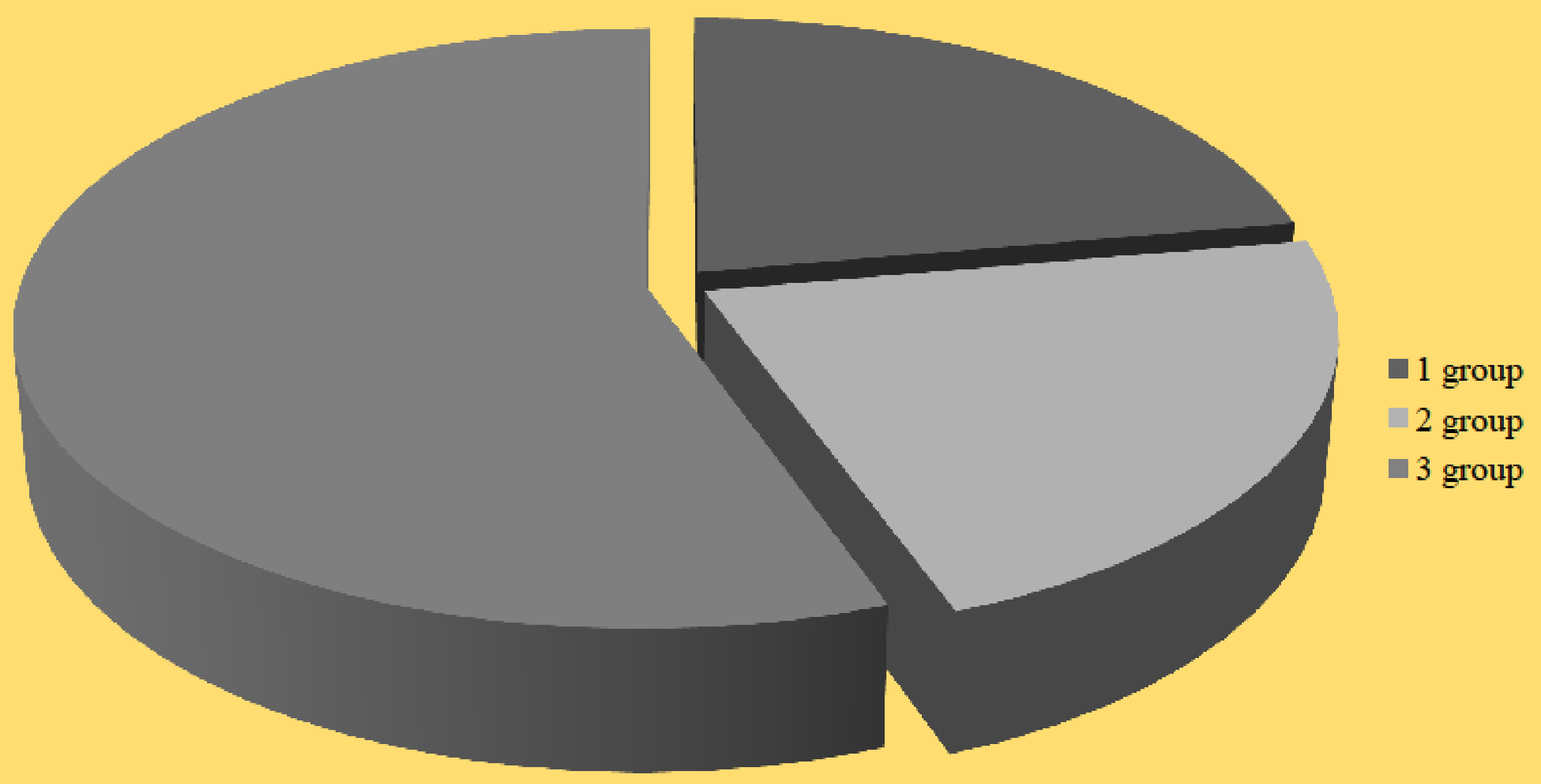

ULTRASONOGRAPHIC SIGNS OF NAFLD

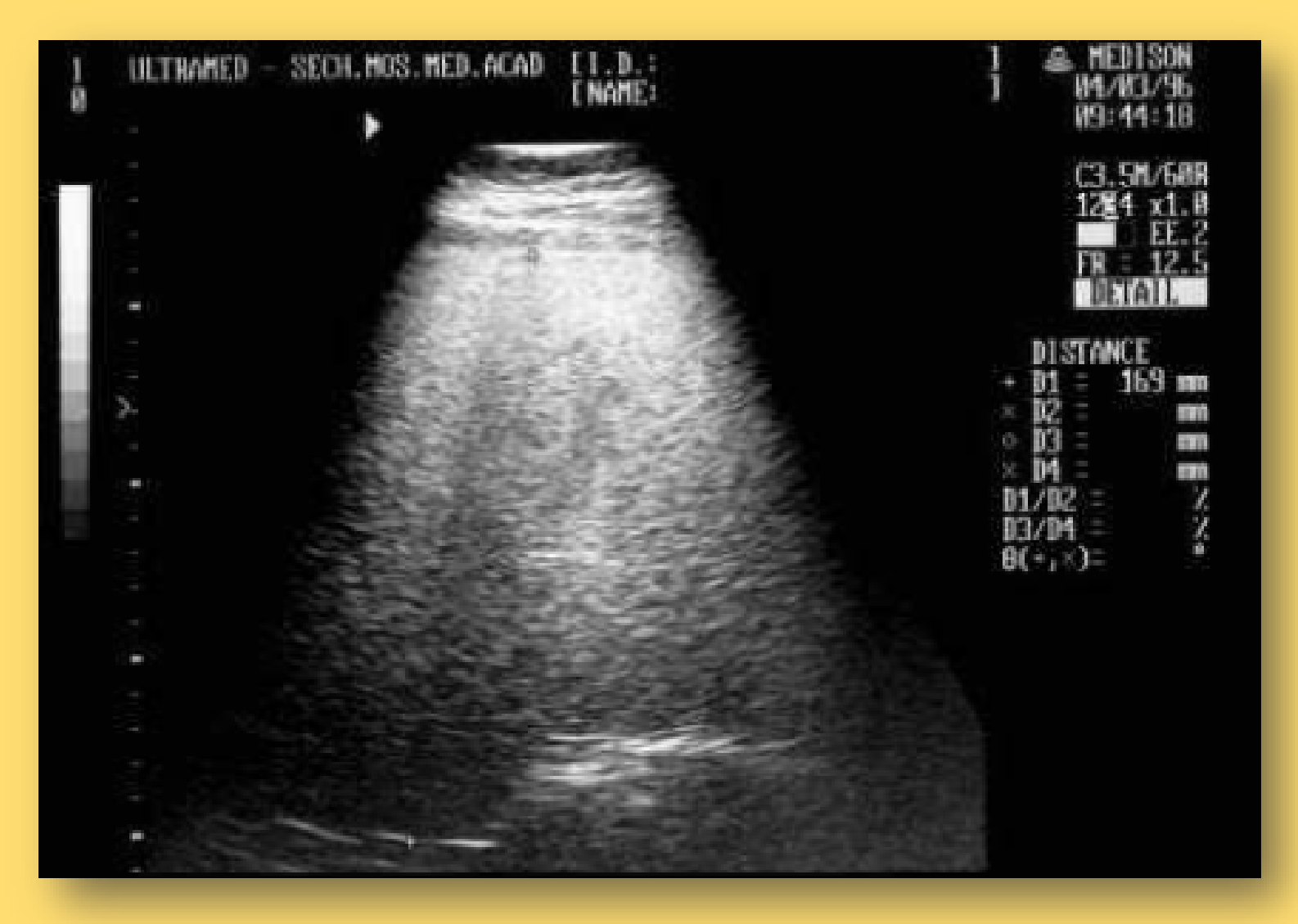

$\checkmark$ diffuse enlargement of hepatic parenchyma "brightness";

$\checkmark$ blurring of vascular pattern;

$\checkmark$ distal echo attenuation;

moderate hepatomegaly $(\mathrm{p}<0.001)$ increased in all groups in comparison with the controls, where it was $(24.21 .06 \mathrm{pkg} / \mathrm{ml})$, the level was the highest in group 3 $(96.60 .72 \mathrm{pkg} / \mathrm{ml})$ and was significantly different from that in groups 1 and $2(66.21 .07 \mathrm{pkg} / \mathrm{ml}$ and $86.41 .21 \mathrm{pkg} / \mathrm{ml}$, respectively), fig.2. In groups 1 and 2 the correlation was established between TNF- $\alpha$ and IRI $(\mathrm{r}=0.33, \mathrm{p}<0.05$ and $\mathrm{r}=0.37 ; \mathrm{p}<0.05$, respectively). In group 3 (with comorbid disorder and obesity) the significant correlation was established between the level of TNF- $\alpha$ and FBG $(r=0.46 ; p<0.05)$, IRI $(r=0.78$; $\mathrm{p}<0.05)$ and HOMA-IR $(\mathrm{r}=0.64 ; \mathrm{p}<0.05)$, fig. 3 .

Fig.2 THE LEVEL OF TNF-a IN PATIENTS WITH NAFLD AND IN COMBINATION WITH T2DM

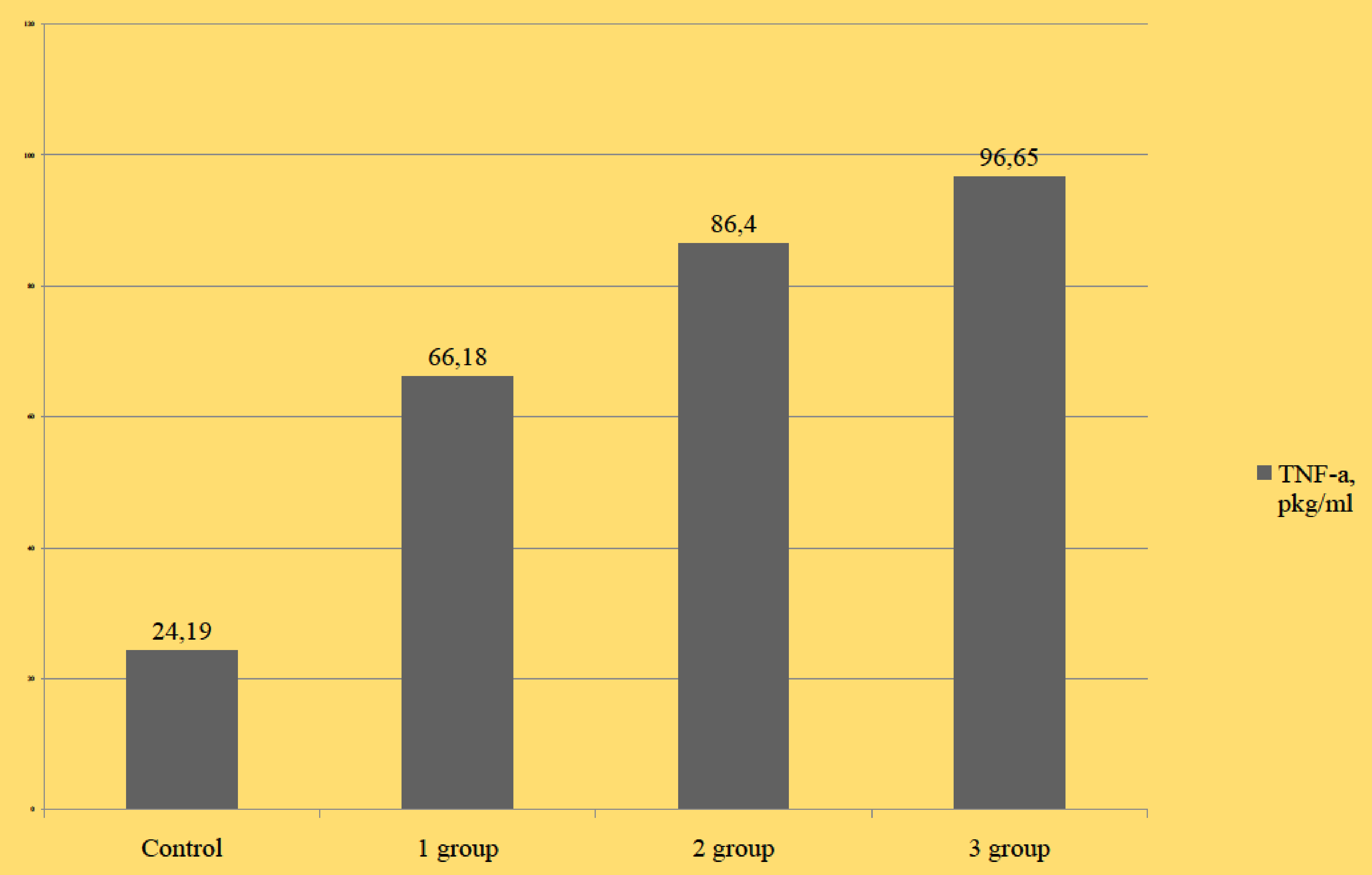

Fig.3 THE INDEXES OF CARBOHYDRATE METABOLISM IN PATIENTS WITH NAFLD AND IN ITS COMBINATION WITH T2DM WITH DIFFERENT TROPHOLOGICAL STATUS

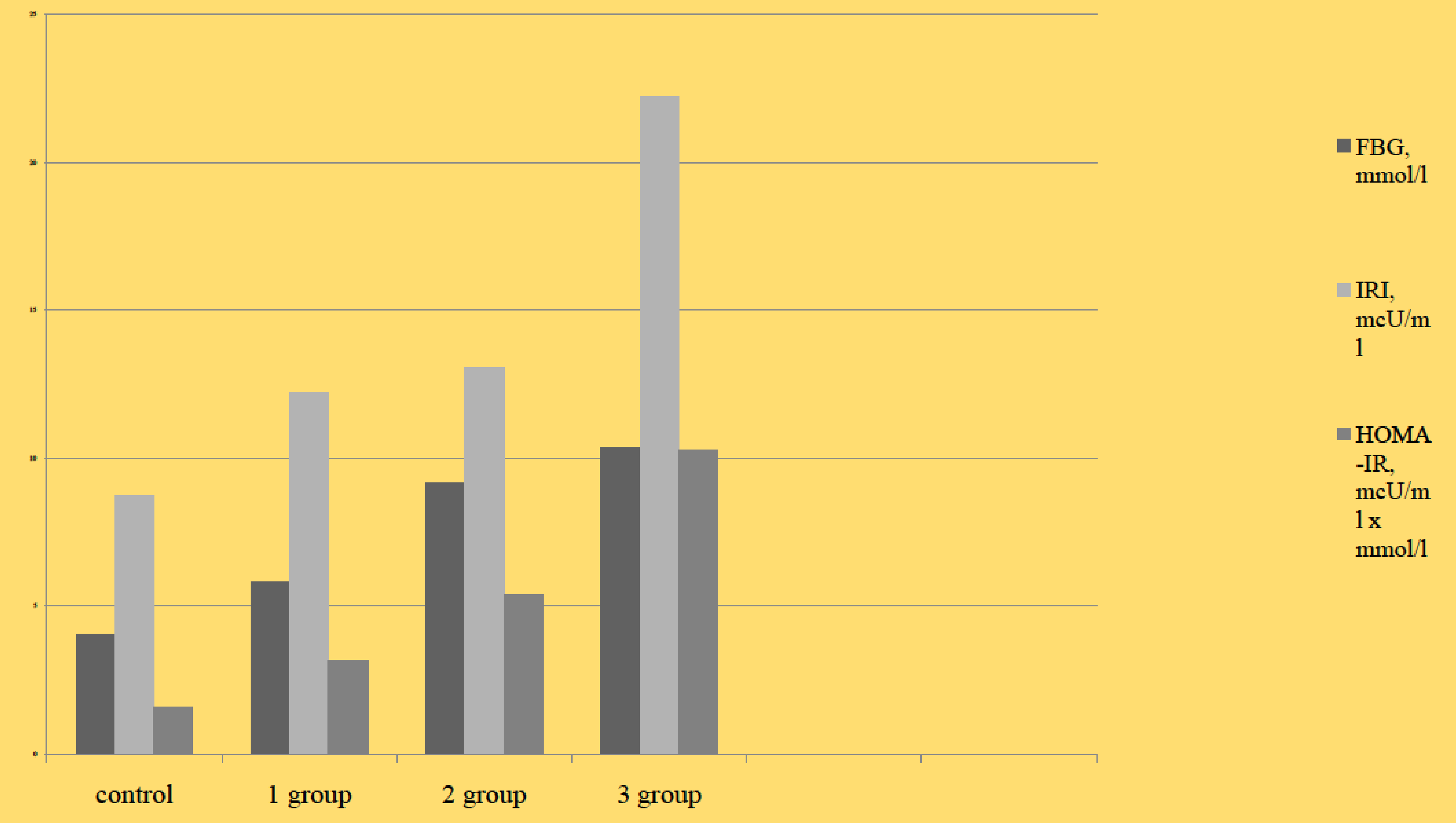

Conclusion. The present study demonstrates that correlation between TNF- $\alpha$ and indices of carbohydrate metabolism is connected with the ability of TNF- $\alpha$ to enhance the carbohydrate metabolism, insulin resistance, and support the role of TNF- $\alpha$ in pathogenesis of NAFLD, namely, in damage of hepatic gluconeogenesis, especially in patients with associated T2DM and obesity. In addition, isolated NAFLD can independently cause the metabolic consequences.

Determination of TNF- $\alpha$ level can provide an opportunity to assess the risk of progression of carbohydrate metabolism disorders on an early stage. 